DOI: 10.20472/TEC.2019.007.014

\author{
STEPHANY VEUGER \\ Northumbria University, United Kingdom \\ SETH RACEY \\ Northumbria University, United Kingdom
}

\title{
STUDENTS AS PARTNERS : ON DEVELOPING A STUDENT LED CONFERENCE TO ENHANCE THE SKILLS OF UG PROJECT STUDENTS
}

\begin{abstract}
:
An important final year assessment which is common to most UK Undergraduate (UG) degree programmes is the final year project or dissertation. It is considered the capstone module on degree programmes whereby students gain valuable skills valued by employers. Our project engages final year UG students in a collaboration designed with inclusivity and partnership in mind.

We ran student-led conferences to communicate the experience of final year students and disseminate their top tips to level 5 students. The project sits across three disciplines in the health and life sciences, the largest faculty in Northumbria University with the aim of developing a widely applicable solution for use across different programmes, departments, faculties and universities. By placing the student experience at its heart, our project seeks to enhance support for student learning through the improvement of graduate attributes including independence of thought and action, curiosity and critical thinking. Thus, employability outcomes are enhanced.

The Project conferences aim to respect the diversity of the student body while creating a sense of equality to 1) support supervision quality across the institution. 2) Improve academic experience and 3) enhance graduate characteristics and thus employability.

The inclusion of students as partners in pedagogic research in the student-led conferences and in a reflective exercise on the inclusion of students as equal partners in pedagogical research encouraged self- management of their own project and supervisor/student relationship thereby enhancing the student experience whilst developing their key graduate attributes.

Student researchers played a major role in data analysis and evaluation. Additionally an eLearning platform organisation site has been constructed continuing the key resources for staff and students alongside video recordings of student presentations.

This scalable project supports the development of graduates that are distinguished by their intellectual expertise and employability through meaningful pedagogical research that maximises student satisfaction.
\end{abstract}

\section{Keywords:}

Undergraduate, Research, Graduate, Skills, Partnership, Conference

JEL Classification: 123 


\section{Introduction}

The significance of the UG project is deemed to arise from its unique status in the programme as the most sustained research heavy piece of work that students undertake during their degree that involves self-directed study. It is as a 'capstone' whereby students put into practice at level 6 the research skills they have acquired in levels 4 and 5. Moreover, the UG research project has the potential to provide up to $40 \%$ of the marks used to calculate their degree classification. The dissertation is often considered a journey towards independent thought achieved through a shift in focus from teacherdirected to self-directed learning. It therefore offers the potential for the further development of specific graduate attributes and skills (Healey et al., 2014). Graduate attributes of contemporary knowledge, critical analysis, employability and research skills as well as cultural and ethical awareness are the key goals of the Northumbria Graduate. The success of the research project is critical in the development of graduate skills. Employability of graduates is a key metric by which universities in the UK are judged. Employment of students after graduating is captured in the Destination of Leavers from Higher Education survey (DLHE) and used as a key measure of quality in the Teaching excellence framework (TEF).

Anecdotally, supervisors distinguish supervision from other forms of teaching, viewing the UG project as a unique opportunity for the student to venture into a new territory where authority and relationships are reconfigured (Todd et al., 2004) whilst students comment that taking responsibility for their own learning can create uncertainty and some may question their capability to conduct independent research.. The literature reports that issues for students often include anxiety, isolation, lacking a clear structure and feeling thrown in at the deep end (Calvert and Casey 2004).

We have been running a project for 4 years that seeks to improve the UG experience of the final year research dissertation. We have previously published our findings on the expectations and perceptions of final year undergraduates and staff in a large applied sciences department at a UK university (strand 1 of the project) (Veuger et al 2018). Throughout the running of the project, we have sought to provide structure and support to dissertation students and supervisors alike by developing research informed resources that are accessible, engaging and student centred. Importantly, we hope to provide a widely applicable solution for use across different programmes, departments, faculties and Universities. An important output from strand 1 included the development of a making supervision work leaflet and a list of discussion points aimed at making supervision more effective without being prescriptive. The suggestion of a student-led conference whereby final year students present to second year students as a mechanism 
to prepare second year students and allay feelings of anxiety was also proposed by students.

Bearing in mind Fielding's (2001) description of students as "radical agents of change" and his call for more emancipatory and participatory methods, we made a commitment to work as a team of researchers in strand 1 as well as during the organisation of student led conferences in strand 3. The opportunity to learn with and from students was presented by the HEA 'Students as Partners' strand of research. Indeed, engagement through partnership is an effective approach for enabling students and staff to authentically engage, opening up opportunities for collaborative and transformational educational experiences.

A key focus has been to understand how we can involve students as partners in pedagogical research in order to drive change through participatory action research (PAR). PAR believes in the active participation of both teachers and students (Kemmis 1986), it emphasises team work and collaboration - working together to analyse the problem and generate actions to solve it. Healey, Flint and Harrington (2014) define four overlapping areas where student partnership in research may occur. "The ethos of partnership is underpinned by values of authenticity, inclusivity, reciprocity, empowerment, trust, challenge, community, and responsibility; made possible through a learning environment that facilitates honesty, openness, and mutual respect" (Healey et al. 2014).

In line with this, we have sought to understand the benefits for student co-researchers in terms of employability and development of their graduate attributes (strand 2 of the project). We have also run two student -led conferences in Health and life sciences at Northumbria University; Applied sciences (2018) and applied sciences in collaboration with sport and psychology (2019). Here, final year students shared their experiences of carrying out a research project and their top tips with second year students who are anxious about their high stakes final year module of which they know little (strand 3 of the project). Moreover, as part of strand 3, the resources developed in strand 1 were trialled by both staff and students. Here, we describe our findings from strands 2 and 3 viz:. the benefits to student researchers of being involved in pedagogical research, organisation and delivery of UG project conferences and benefits for student conference attendees by fostering the development of an online organisation site that we believe represents a community of practice.

\section{Methodology}

This project is identified as qualitative, participatory, small-scale pedagogical research. As such, it is an interpretive project with a focus on understanding the subjective 
experience. Specifically, because the project is interested in how student experience and identity has come to be as it is, the project also draws on social constructionist principles. In working with students as equal partners, the project was participatory and aspects of the project design (e.g. the detail of the conference organisation) were to be co-designed with students The qualitative approach focussed on generating experience narratives of student co researchers on the topic of how they experienced being involved in pedagogical research as equal partners with staff. Specifically, we sought to ask whether involvement in pedagogical research enhanced their 'Northumbria graduate attributes'.

Blood and Wood (2006) refer to PAR as a dynamic and cyclical process which moves through phases of planning, action, observation and reflection. Our study has involved cycles that for ease, we refer to here as strands. It should be noted that the strands oversimplify the social context of our research and the process was not necessarily as sequential as suggested here.

Research Project strand 1 : Students as researchers supported in their role by tutors. Uncovering the expectations and developing resources to support the research journey. Students developed questionnaires and undertook semi structured interviews with other students and supervisors (Discussed in Veuger et al 2018).

Research Project strand 2 Tutors as researchers, investigating the experience of the student researchers of being involved in the project. The student researchers were supported to reflexively consider how participation in this project developed their identity and skills as a researcher. 3 student researchers from strand 1 discussed their thoughts in depth through focus groups and semi structured interview.

Research project strand 3 Students as organisers, presenters and peer supports, supported in their role by tutors.. In 2018, 14 students were recruited from Applied sciences and in 2019,10 students who had just completed their project module were recruited from three disciplines within health and life sciences (Applied sciences (5), Sport (3) and Psychology (2)) ran and an UG conference with support from staff. The Students organised, delivered and chaired the UG project conferences. Student presenters were supported to reflexively consider the benefit of the project module to them and then communicate this to students who will embark on the project module the following term. 10 students who had just completed their project module drawn from the three disciplines (Applied sciences, Sport and Psychology) ran and delivered the UG conference supported by staff.

In strand 1 during focus groups in which the students identified major themes for support. This lead to the construction of a questionnaire and visual aid that students and staff could use at the start of their project module to uncover student and staff expectations, 
supervisory styles and support needs in a semi structured open dialogue. Student researchers with support from staff tested the resource produced in strand 1. 12 /67 from staff Applied sciences trialled the leaflet in applied sciences including staff involved in peer support. Following the trial at the first meeting with their project students, staff were requested to complete a questionnaire that was co-designed.

\section{Sampling}

The sample of final year (level 6) student organisers and presenters in strand 3 ( $n=14$ 2018; $n=10$ 2019) came from the faculty of health and life sciences (2019 - Applied sciences (5); Sport (3); psychology (2) ). Student organisers/presenters were recruited from the final year cohort. They were identified through a combination of purposive and convenience sampling. Recruitment was via a central email on the dissertation e learning portal. There was no solicitation of volunteers. It was made clear that participation is voluntary. The process of consent included the opportunity for questions about the research to be raised. All presenters signed a GDPR consent form to be videoed and to allow the footage to be used for future students through an organisation site with a sign in. Students are afforded the opportunity to withdraw consent at any time and have their content removed from the site. Signature of the GDPR was voluntary and not a prerequisite requirement to present or organise the conference.

Second year (Level 5) student attendees were invited via a central email posted via a message on the e-learning portal of a large module attended by all. Student attendees were requested to register their interest via a mailbox set up specifically for this purpose. Both student and staff organisers manned this mailbox. Student organisers also drew on their knowledge of their own academic and social networks to raise awareness of the event through snowball sampling.Student organisers designed a poster to advertise the conference to the rest of the student body. This was distributed on social media by the students and on the electronic learning platform by the staff.

\section{Study design}

Student interviews following both strand 1 and student led conferences were semi structured to encourage discursive dialogues. Specifically the interviews related to the themes : understanding graduate skills developed, change in identity as researchers

Discussions focused on what worked and what could have been done differently. The interviews emphasized that a ) the process is appreciative -think about 'what worked', 'what did I gain', 'what would be even better if' and b) the purpose of the activity was to appreciate their experience and insights, so there are no right answers 
Much of the feedback gained from conference attendees were voluntarily provided by email.

The conference was co designed between the staff and the student organisers. A generic conference presentation frame work was provided by staff. Student organisers then adapted the framework and identified chairs for each of the sessions. A conference programme was co-constructed with presenters, project topics and abstracts were provided. Chairs were responsible for ensuring that presenters kept to time and chaired a question and answer session after each presentation.. The conference itself was delivered as a separate full day session which students could drop in to and drop out of. Coffee and lunch breaks were provided in break out rooms to encourage discussion in an open forum with both students and staff.

\section{Focus groups}

These were conducted in the context of training, briefing and supporting student organisers in planning, setting up and running a student led conference.

\section{Data analysis}

Analysis of open ended responses to interviews took a grounded approach. The project therefore generated reflective and reflexive data. Transcripts were subject to basic coding analysis to generate themes.

\section{Ethics}

Ethical approval was received through the university process. Due ethical considerations were given to issues such as access, consent, confidentiality and harm. All questions were designed to minimize risk of psychological discomfort or distress. Al individuals were allowed to influence the work. Decisions surrounding the research are collective, a central philosophy of PAR. Development of the work remains visible and open to suggestions by all researchers and some students remain involved in the work.

\section{Results}

\section{Students as partners: enhancing graduate attributes}

3 students from strand 1 gave detailed comments through semi structured interviews (strand 2). 24 students in total ran and presented at the conferences across the 2 years. 
All gave informal feedback via email or face to face and 5 consented to semi structured interviews (strand 3).

During strand 2, the 3 student researchers from strand 1 were asked to reflexively consider how involvement in this project has enhanced their graduate attributes. A summary of the key points they made is shown in figure 1 below. Comments fell under the broad themes of leadership, analytical skills, knowledge gained and responsibility. Within these themes, sub themes of developing creativity, influencing others and a sense of growing researcher identity were identified. Two students have written statements of support (appendix) and they both came back following graduation to present a poster at a teaching quality enhancement day. Both felt strongly that they wanted to give something back and raise awareness of the benefits for students and staff in engaging students as partners in research.

Figure 1. Student researcher voice: Summary of student researcher reflection on their development of Graduate attributes.

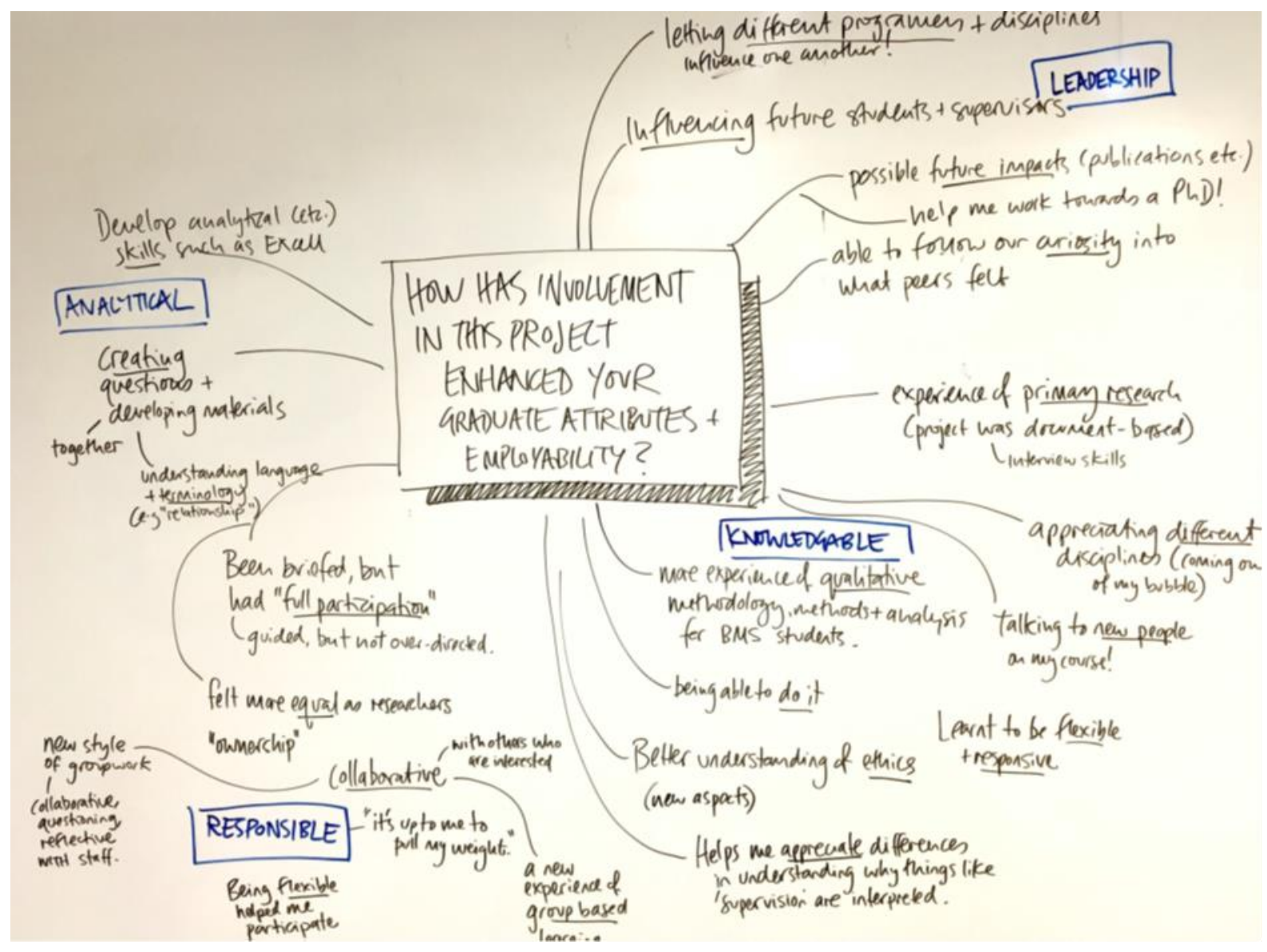

Source: author created 
All students felt that through being equal partners in the research, they had developed a new sense of researcher identity "Involvement in this research project challenged my identity as a student" student researcher 2. By doing so, skills valued by employers including leadership skills had been strengthened and developed "My involvement in this study as an extra-curricular activity has shown employers that I have initiative and am driven" Student researcher 3

An important benefit outlined by students was the opportunity to explore and gain knowledge and skills within a discipline different to the one they had studied "My involvement in this project as a student researcher gave me a unique opportunity as an applied science student to conduct research external of the laboratory" Student researcher 1. "Working alongside lecturers with experience in the subject area, helped me develop as a researcher, and increased my knowledge especially regarding qualitative research and analysing it' .Student researcher 3

Students were often invigorated by the opportunity to be part of a conference team and to give something back to their degree programs by presenting at the conference. Attendees reported verbally that they really enjoyed the opportunity to gain an understanding of their project module and the student experience of it prior to commencing their own projects.

Student conference presenters and organisers unanimously feel they have really benefitted from their involvement in this project and one student remained involved following their graduation in 2018. This student felt so strongly about her personal gains that she volunteered to present to the senior management at a faculty showcase on how she has benefitted and the graduate attributes she feels she has strengthened and developed. The running of a student led conference was rolled out across 3 departments in 2019 (applied sciences, sport and psychology).

Reasons given for volunteering included self-development, such as improving communication skills and improving their confidence. Interestingly, the majority of those who volunteered to present are students who would identify as having low confidence and a lot of anxiety around presenting in front of an audience. Further to self development there were also the more altruistic reasons of supporting others ".....I never thought l'd say it but l'd love to help other people feel less anxious about things even if I myself feel anxious in the process. "Student presenter.

"Doing the presentation for people l'd never met before really boosted my confidence and I was happy to help other students with an issue I came across myself.... It was a fun experience that made me feel like I've done something good." Student orgnaniser and presenter 
Top tips given to second years were grouped into key themes of - being organised and communication with sub themes of, 'timekeeping' and 'asking questions'.

"You may feel anxious at the idea of going into the lab and having to work independently which is different to anything you may have done before but fight that anxiety and prove to yourself that you can do it. It will be the best thing you do and you'll be better prepared for whatever you go onto next." Student presenter

Benefits to organisers and presenters reflected the reasons they had given for volunteering - with broad themes of improving confidence, organisation skills, reflection and critical thinking skills, responsibility and communication skills. Some of these echo our previous findings (Veuger et al 2018) ; confidence and independence are gained through working in partnership with staff - both important graduate skills valued by employers.

"I personally got out of doing the conference a huge boost in confidence and feeling like I've made a difference in hopefully easing some anxiety for 2nd years that way they won't feel as daunted by the idea of doing a project and walking into the unknown" and" It has given me a an insight into working with other people on a professional manner which is a great thing to take away especially in my next steps as I'll have to work as a multidisciplinary team but also a boost in being able to trust myself to work independently."

Presentation and communication skills were improved and discussion amongst students were considered valuable as a means to support one another through the sharing of common concerns. Acting as chairs gave presenters a feeling of responsibility and was perceived as less threatening to the student audience.

"Thank you for including us in organising a conference ...... it was a great opportunity for us to practice presenting and get talking with other students."

"Through this conference I believe to have developed my presentation skills, presenting a topic to a group of people that don't necessarily know much about a specific topic but still make it interesting and to the point can be a challenge, but $i$ believe to have achieved that."

Attending the conference was an excellent opportunity for second years to engage with speakers and see examples of dissertation projects - whilst reducing anxiety, the conferences also serve to promote skills of critical analysis when listening to and responding to speakers with questions as well as thinking about their own expectations of their project and identity as a researcher. 
".. I really enjoyed it yesterday and the student I spoke to seemed to feel like it made them more prepared."

"I just wanted to say thank you so much to you all.....It has allayed a lot of my fears about the module and given me lots of tips that I will definitely be implementing in September! It was a massive help to hear about the actual process and what other students have experienced as well!"

\section{Trial of resource}

The resource has been trialled during phase 3 via two mechanisms; (1) peer support with 2 staff from. Applied Sciences and (2) academic supervisors were all sent the resource via email and asked if they would use it with their students at the first meeting. Of 67 staff, 12 used the resource and fed back both student thoughts and their own via a questionnaire.

Suggestions following peer support discussion were that perhaps the students should write up answers to the questions and both student and supervisor sign the final 'agreement'. A full statement of support from one member of staff was provided (appendix). .One point that came through during discussions with supervisors during peer support was the positive role the resource played in making clear the expectations of both the student and supervisor thus allowing for a stronger partnership; one that enables students to be more proactive whilst providing a mechanism for students to highlight to staff the needs of each individual student. "From the conversations I had with my students, clearly there was an impact. Two of the discussion points which attracted the most comments are: 'Who will be responsible for arranging contact' and 'Who will keep a record of meetings'. The former made the students realise that they should actively seek for help/guidance when it is needed and the latter promoted them to use their notebook much more effectively avoiding repeated discussion or briefing. ". Applied Sciences Supervisor

"The exercise also helped me better understand the students' needs and styles. Thus I could support them more effectively". Applied Sciences Supervisor

Moreover, supervisors found that the resource supported the process of developing independent thought;" Together, the 'Points for discussion' served as a checklist helping the students better manage/organise their project work and triggering them to do much more thinking " Academic supervisor

The resource is also a mechanism to support students in thinking and engaging earlier with the process, "The students reported that they thought it was a really good idea as it 
prompted them to think about aspects of the project they had not considered which prepared them more effectively for the project (literature searching, reading, expectations of the lab etc.)."

Linking back to our findings and main themes in strand 1 which led to the development of the resource, staff comment that it is a valuable means by which student fears can be allayed early on by outlining the process and the support available (Veuger et al 2018).

"All of the students stated that it actually reduced their anxiety as they realised they would not be expected to carry out lab work without guidance or be expected to devise experiments. " and "it answered some of the questions they had about the project but weren't confident to ask". Academic supervisors

This was echoed by student feedback on the resource,

. ".....allowed me to identify what emotional, educational and practical expectations I had from my supervisor and vice versa which helped me adapt my learning experience."

Not all supervisors chose to use the resource with their students and of the 12 , one supervisor did not find it useful, "I think that each supervisor has their own style of managing project students and maybe this is a little too rigid in structure for some to use comfortably." Academic supervisor

Student feedback was all positive. One repeated theme was that of 'asking questions'. In strand 1, being able to ask questions was a major theme identified from semi structured questionnaires and interviews which serves to help students feel calm and supported.

"I like the points of discussion because they correlate with some of the questions I know I had in the first meeting. "

\section{Discussion}

\section{Students as partners}

Several case studies have been reported in the literature exploring students as partners (SaP) (eg. Cook-Sather et al. (2014) Cooper (2014)). Pauli et al (2016) investigated the impact of teaching and learning methods aimed at fostering partnership in UG students. Wenger's (2000) notion of a community of practice, defined as "groups of people informally bound together by shared experiences and a passion for a joint enterprise" had a particular resonance to our work. Healey, Flint and Harrington's conceptual framework 
helped us locate our research as "co-researching and co-inquiring", somewhere in the overlap between "subject based research" and "scholarship of learning and teaching." (Healey et al 2014). This study investigated the inclusion of students in subject-based inquiry, as well as the scholarship of teaching and learning where students engage in pedagogical research. Therefore, students were not only involved in carrying out research towards their final UG project, but engaged alongside staff in pedagogical research into the student experience. Working in partnership with students has been suggested to be one of the two principles of good practice of scholarship of teaching and learning (SoTL).

Student comments allowed us to identify a number of benefits to students who are involved in pedagogical research (strand 1 and strand 3) including enhanced confidence, critical thinking skills, independence and communication skills. The opportunity to work as a team and take responsibility were also key benefits to organisers and presenters. Through final year students presenting the project experience and guidance to second year students there was real value by providing an authentic lived experience of the project module. This provided important peer support to the second year students who had identified at programme review meetings that they were anxious about the high stakes module and how it runs. Providing a forum for second year students to ask questions of the final years and then explore their experiences allowed students to gain a valuable understanding of the project module and what they can expect as well as receiving tips on how to succeed. Together, this served to alleviate a lot of their anxiety over what was to come and enable them to begin to feel prepared.

\section{Enhancing graduate skills}

Graduate attributes are the knowledge, qualities and skills a University agrees its students should develop during their time with the institution. Ultimately, they shape the contribution that graduates make to their profession and society. They are qualities that also prepare graduates as agents of social good in an unknown future. (Bowden et al. 2000; cited in Barrie 2007). Northumbria University was ranked as 9th for the number of graduates in professional employment in the destination of leavers for higher education survey 2016. The characteristics of a Northumbria graduate, underpinned by the research rich learning pillar, are that students are expected to develop as critical scholars and to have graduate attributes of thinking independently; challenge thinking; communicate effectively; solve problems; apply knowledge; work constructively in teams and value curiosity. Many studies have identified the role of UG research in students' cognitive, personal and professional development (Hunter et al. 2007), many of which are valued by employers. Spronken-Smith and Walker (2010) identify the added benefit that inquirybased approaches can "help to facilitate an academic community of practice including both academics and students". With the implementation of the teaching excellence frame 
work in the UK graduate employability has come to the fore as key metric by which university success is measured. The employment outcomes of graduates are assessed in the Destination of Leavers from Higher Education survey (DLHE) (https://www.hesa.ac.uk 2019) and used as part of a tripartite metric of: student satisfaction, student continuation in study and employability. The TEF metric is then used to rank university quality as Bronze, Silver or Gold. Those universities that are most successful in the TEF gain a reputational increase and are likely to been seen as more attractive to potential students. TEF success is therefore critical in the HE sector in the UK as the forecast for 18 and 19 year olds who are likely to enter HE falls by 8.4 per cent between 2016 and 2022 (OBR 2018). Resulting in increased competition for students enrolments across the HE sector.

In the UK the Teaching Quality Enhancement Fund gave universities, since 1999, extra money to focus on initiatives focused on teaching improvements (Gunn 2018). These are focused on improving the TEF metrics of which employability is a key measure. Embedding employability in higher education is a drive in the HE sector (https://www.heacademy.ac.uk 2016) especially as the TEF refocuses away from unreliable measures like student satisfaction and toward employability (Grove 2017).

One of the key approaches common to most UK universities is to use a final year project or dissertation module to foster research skills and independence in the student skill set as a key. We show that supporting this process through students as partners and peer supporters enhances the development of these skills.

The Student led undergraduate conferences are a key approach to embedding a research culture in the curriculum (Garde-Hansen Calvert 2007). The research described here extends these findings by highlighting the potential of collaborative pedagogical research to change the nature of the staff-student relationship and develop a culture of partnership. By being a part of this project, the student organisers/presenters were able to rethink theoretical concepts and practical issues in ways they had not considered before. It gave students a sense of identity and improved their confidence. Indeed, Pauli et al (2016) espouse the long-term value of SaP experiences in relation to employment and further study and discuss the impact of SaP pedagogies on graduate attributes in UG students. Indeed one student who had entered the project with anxiety and self confidence issues presented a summary of project outcomes in front of university senior management at a faculty workshop. She viewed the project as a transformative process that resulted in gaining the skills and attributes required to embark on an research career at Canadian university. In line with the findings of Crawford et al (2012), partnership was experienced by the student researchers in this research as having a positive impact on how they developed a range of desirable skills; this includes relationship building skills, communication skills, 'learning to learn' skills and underpinning these, a sense of growing personal confidence. 
Although each student came to the project with their own motivations (ranging from enhancing employability skills through to altruistic motivations to help future cohorts) and views of what was most pressing to consider, working on a 'real' project - by which I mean, one which involves pre-existing challenges, involved others and required the intellectual exploration of ideas in practical ways with the aim of action served to focus students' attention on shared professional concerns. I have to come to believe strongly that learning and working in partnership meant that those involved grew through actively engaging in the process of achieving mutually beneficial objectives. All students agree that they have enhanced their skills rated by employers. One limitation, however, is that at present inclusivity is limited since only some students are researchers. We may therefore have unwittingly created inequality amongst the students.

"Sharing is central to the concept of partnership: shared goals, shared power, shared risks, shared responsibilities, shared learning and shared values (Bird and Koirala 2002, cited in Cook-Sather)". The concept of partnership therefore challenges established structures of power and influence, and raises new questions. We aimed for students to be recruited and run the study alongside the staff researchers -to be co-researchers- where the study becomes one of co-operative research thus forming a research partnership and the power relationship is one of equal partnership (Archer and Whitaker 1994). As qualitative research is about a communicative process and forming relationships, we cannot ignore the power differentials between the participants in the study. The use of students-as-partners aimed to engage students in ways meaningful to them by treating them as respected and trusted adults. This does not imply equality in power or knowledge but it is respectful to them as learners and of their life experiences, diversity and individual needs.

Ordinarily, in quantitative research, there is a hierarchical relationship between researchers and participants which has the researcher doing the thinking and the participant the action.

We sought to foster a co-production of knowledge thus minimising notions of ownership by the staff researchers (Wolf 1996) but rather emphasise the co-construction of knowledge in line with constructionist views. This is a student-centred approach. Here, both researcher (staff or student) made contributions and the relationship between them is important . I briefly want to consider the power relations between staff researchers and student researchers, student researchers and student participants and student researchers and staff participants. Reflexivity was important to engage with power imbalances and to consider the validity and reliability of interpretive research (Koch and Harrington 1998) and reflection on motivations, beliefs and methods was key to each focus group. 
We can see that in fact there are a range of power relationships from highly hierarchical (researcher and participant represented by interactive poll) through lower hierarchical through to egalitarian relationship which we were striving for at the beginning of the study through engagement of co-researchers.

The relationship between staff researchers and student researchers changed with time and was influenced by personality, world view, social background, methodology and personal goals. We employed students as co-researchers to minimise the hierarchical atmosphere and instead provide one that is anti-authoritive and promotes a feeling of empathy thus enabling student participants to more readily open up in an environment of power equality.

\section{The way forward: meeting in the middle}

The resources and findings, developed collaboratively with student researchers as equal partners and with equal voice, aim to support current practices in the undergraduate project without being prescriptive in terms of supervisory style. It is important that staff do not see this as a prescriptive mechanism on how to supervise. Unfortunately at least one member of staff appears to have misunderstood the intention of the resource whilst others have not used the resource at all, It is clear that the use of the resource as a support to open dialogue between student and supervisor needs to be clarified. Our resources are only meant as a scaffold to support discussions between each supervisor and each student - to enable expectations to be clarified and agreed on. The key issue is that students feel heard and they know what to expect and what is expected of them for their particular project. This is important since factors that are known to increase engagement include 'belonging'. This is achieved through feelings of acceptance and involvement and comes with a move toward independence through an understanding of changing relationship dynamics that foster approachability and a feeling of being respected

\section{Implications for policy and practice}

We believe that the chosen research methodology has succeeded in transforming those involved and will support the practice of future project students and supervisors through an emphasis on the development of practical solutions and collaborative work. Indeed, comments made by student researchers and staff who have trialled the resource indicate that a degree of transformation has occurred. In essence, we will support transformation of practice so that it reflects the need of the students and staff not just prescribed policy. 
For us, this project has served to highlight the complexity of designing PAR that enhances rigour and credibility whilst taking into consideration power differentials .

This project impacts departments across the University, influences practice on UG research modules, encouraging a significant move towards students as active researchers. Interviews with student researchers has shown development and enhancement of graduate employability and attributes. It is clear that involving students in pedagogical research can enhance their learning and professional development. By generating detailed narratives on the student supervisor partnership as well as trialling our resource which importantly aims to respect the diversity of the student body while creating a sense of equality, this project sought to 1) support supervision quality across the institution 2) improve the academic experience and 3) enhance graduate characteristics and thus employability.

This collaborative project is in line with the TEF which seeks to improve teaching quality and the learning environment through resources and scholarship. Moreover, our resource(s) will promote a feeling of personalised learning by helping to tailor the supervisory experience to the individual and thus maximising attainment. This scalable project therefore specifically aligns with the following strategic outcomes ; graduates that are distinguished by their intellectual expertise and employability ; high quality meaningful pedagogical research and maximising student satisfaction.

\section{Limitations}

We used a top down approach to our PAR which some would consider problematic (Low 2000). Here we invited students to take part and address relevant questions. However these questions and the study design were then refined by those co-researchers . ideally, students would have contacted us to initiate a project however, as Teram et al (2005) state "it would be unethical to delay action on this as we were already aware" of the perception of disparity and a need to understand the UG dissertation experience from student and supervisor points of view.

\section{Conclusion}

Sharing knowledge enables the production of richer ideas. A lack of project sustainability can be avoided if those involved in learning and teaching (deliverers and users) work together. This collaborative enquiry based approach sought to create meaningful change and promote ownership of the interventions produced. It has a number of strengths, particularly the ability to provide a robust real world application where the research activity responds directly to the needs of the participants. 
This project has served to highlight the complexity of designing PAR that enhances rigour and credibility whilst taking into consideration power differentials. On a practical level, all participants in the study have developed a new range of skills valued by employers. This project is readily scalable and we strongly believe that this strategic collaboration will see improvements in the student experience of UG research projects whilst enhancing not only the students undertaking their projects but also those student partners involved in organising and presenting at the conference.

\section{Appendix: Statements of support from student researchers and peer support partners}

\section{Statement of support Student 1 (Student participant and researcher)}

The dissertation of a final year undergraduate student is regarded as the most important assessment and the consummation of an undergraduate degree. This project, which studied the expectations and realities faced by students and staff throughout the dissertation journey, was the first of its kind for applied sciences at Northumbria University. Although the dissertation is designed to be a student-directed learning experience, it was uncovered that many students felt that inappropriate support was available during this learning transition. An important aspect that this project unravelled was the different themes of expectations amongst students and staff. These included emotional, educational and practical support. It became apparent that due to a lack of framework, inconsistencies were seen by both students and staff that resulted in discontent. Importantly, the results of this study have been used to develop tools and resources that are designed to alleviate some of these inconsistencies and act as a point of guidance for students and staff. It is hoped that these resources will be included in the future module guides of applied science degrees.

Similar studies have been conducted on experiences of the dissertation journey however, few applied science students have been involved in such studies and often the supervisor's perspective is not included. This project was important in identifying disciplinary differences firstly between institutions and secondly between departments. My involvement in this project as a student researcher gave me a unique opportunity as an applied science student to conduct research external of the laboratory. This has developed my skills set and has noticeably improved my graduate attributes. My involvement in this study as an extra-curricular activity has shown employers that I have initiative and am driven. Through the interview process of the project, I was able to reflect on my own experience during my dissertation as this was going on at the same time. It allowed me to identify what emotional, educational and practical expectations I had from my supervisor and vice versa which helped me adapt my learning experience. 
Involvement in this research project challenged my identity as a student. Although an undergraduate student at the time, this project gave me the opportunity to been seen as equal to established researchers. This boosted my confidence and taught me valuable skills such as study design, organisation and interpretation of qualitative results. Additionally, being involved in this project has given me pride that the results will improve the dissertation journey of future students.

\section{Statement of support Student 2 (Student participant and researcher)}

The TQEF project allowed me, as a final year undergraduate student, to gain an insight into a different field of research. Having only experienced research within a biomedical context being able to discuss and design a pedagogical project which could impact future graduates at the university. Working with peers was greatly beneficial to me by learning how diverse people can work on a project and bring different ideas to the table. Working alongside lecturers with experience in the subject area, helped me develop as a researcher, and increased my knowledge especially regarding qualitative research and analysing it. Also, being able to work independently and with other final year students as peers to carry out the project following group meetings was greatly beneficial and increased confidence in our ability to research and communicate.

\section{Statement of support. Academic project supervisor and peer support partner}

The final year project is normally the biggest module in undergraduate programmes, for example worth 30 credits and running across the whole academic year for our chemistry students. Each chemistry academic has to supervise commonly 5 students doing various projects of sometimes very different nature. My analytical chemistry students will use different types of instruments (from spectroscopy to chromatography) and investigate different types of samples/applications (from food/nutritional to pharmaceutical to environmental). Also the students often have different expectations and different styles of learning. All those factors make the project supervision a quite challenging task through the year. The central issue is how to keep the students highly motivated and engaged, so they can actively drive the project work forward instead of passively waiting then following my directions. In the past years I have had all kinds of feedbacks, some of them are exactly opposite (e.g. some students like to be closely monitored and some like to be doing lab work independently once a planning meeting has taken place).

In September 2016, I was paired up with Dr Stephany Veuger for peer support. During our first meeting Stephany introduced her 'Making supervision work' research outcomes (the Points for discussion). We decided to apply them to my undergraduate project students. So at the start of their lab work in semester one, I provided the leaflet to the students and asked them to think about the key points and see how they would respond 
to them. At the start of semester two, I had individual meetings with my project students to find out how the discussion points have helped them so far.

From the conversations I had with my students, clearly there was an impact. Two of the discussion points which attracted the most comments are: 'Who will be responsible for arranging contact' and 'Who will keep a record of meetings'. The former made the students realise that they should actively seek for help/guidance when it is needed and the latter promoted them to use their notebook much more effectively avoiding repeated discussion or briefing. Together, the 'Points for discussion' served as a checklist helping the students better manage/organise their project work and triggering them to do much more thinking and initiating of their lab work, and ultimately improved their learning experience. The exercise also helped me better understand the students' needs and styles. Thus I could support them more effectively.

I would be happy to recommend the leaflet to all my chemistry colleagues in the department.

\section{References}

ARCHER, L., \& WHITAKER, D. (1994). Developing a culture of learning through research partnerships. In P. Reason (Ed.), Participation in human inquiry, pp. 163-186. London: Sage

BARRIE, S.C., 2007. A conceptual framework for the teaching and learning of generic graduate attributes. Studies in higher education, 32(4), pp.439-458.

BLOOR, M. and WOOD, F., 2006. Keywords in qualitative methods: A vocabulary of research concepts. Sage.

CALVERT, B. and CASEY, B. (2004) Supporting and assessing dissertations and practical projects in media studies degrees :Towards collaborative learning. Art, design and Communication in Higher Education 3, 47-60

COOK-SATHER, A., BOVILL, C. and FELTEN, P., 2014. Engaging students as partners in learning and teaching: A guide for faculty. John Wiley \& Sons

COOPER, B., 2014. Students as partners: embracing the new paradigm in mathematics. MSOR Connect.

CRAWFORD, K., 2012. Rethinking the student/teacher nexus: students as consultants on teaching in higher education. 2012) Towards teaching in public reshaping the modern university, pp.52-67.

FIELDING, M., 2001. Students as radical agents of change. Journal of educational change, 2(2), pp.123141.

GARDE-HANSEN, J. and CALVERT, B., 2007. Developing a research culture in the undergraduate curriculum. Active learning in higher education, 8(2), pp.105-116.

GROVE, J. (2017a) 'TEF to limit use of 'flawed' NSS scores', Times Higher Education, 2. February, p8.

GUNN A. (2018) Metrics and methodologies for measuring teaching quality in higher education: developing the Teaching Excellence Framework (TEF),Educational Review, 70:2, 129-148, 
HEALEY, M., FLINT, A. and HARRINGTON, K., 2014. Engagement through partnership: Students as partners in learning and teaching in higher education. Heslington, UK: The Higher Education Academy.

HUNTER, A.B., LAURSEN, S.L. and SEYMOUR, E., 2007. Becoming a scientist: The role of undergraduate research in students' cognitive, personal, and professional development. Science education, 91(1), pp.36-74.

KEMMIS, S. and FITZCLARENCE, L., 1986. Curriculum theorising: Beyond reproduction theory. UNSW Press.

$\mathrm{KOCH}, \mathrm{T}$. and HARRINGTON, A., 1998. Reconceptualizing rigour: the case for reflexivity. Journal of advanced nursing, 28(4), pp.882-890.

LOW, J., SHELLEY, J., \& O'CONNOR, M. (2000). Problematic success: An account of top-down participatory action research with women with multiple sclerosis. Field Methods, 12, 29-48.

PAULI, R., RAYMOND-BARKER, B. and WORRELL, M., 2016. The impact of pedagogies of partnership on the student learning experience in UK higher education. Higher Education Academy, York.

SPRONKEN-SMITH, R., 2010. Undergraduate research and inquiry-based learning: Is there a difference? Insights from research in New Zealand. Council on Undergraduate Research Quarterly, 30(4), pp.2836.

TODD*, M., BANNISTER, P. and CLEGG, S., 2004. Independent inquiry and the undergraduate dissertation: perceptions and experiences of final-year social science students. Assessment \& Evaluation in Higher Education, 29(3), pp.335-355.

VEUGER, S., GALLAGHER, S., CREIGHTON, H., ROBSON, I., COOKSON, L. and RIDLEY, M., 2018, July. Uncovering expectations and perceptions of the final year UG dissertation-supporting the student research journey and enhancing their graduate attributes. In Proceedings of Teaching and Education Conferences (No. 8309566). International Institute of Social and Economic Sciences. Pp76-100.

WOLF, D.L. (1996). Situating feminist dilemmas in fieldwork. In D. L. Wolf (Ed.), Feminist dilemmas in fieldwork. pp. 1-55. Boulder, CO: Westview.

https://cdn.obr.uk/EFO-MaRch_2018.pdf- Office for Budget Responsibility: Economic and fiscal outlook, Presented to Parliament by the Exchequer Secretary to the Treasury by Command of Her Majesty March 2018, Chapter 4 Fiscal outlook Box 4.5: Forecasting student numbers for our student loans forecast pp161

https://www.hesa.ac.uk/news/17-01-2019/sb252-higher-education-student-statistics

https://www.heacademy.ac.uk/system/files/downloads/employability_viewpoint_july16_1.pdf 